\title{
Claudio Paolini: Proyecciones de lo insólito: lo fantástico en el cuento uruguayo del medio siglo XX. Montevideo: Ediciones de la Banda Oriental, 2019.
}

El presente libro, escrito por el director del "Grupo de Investigación sobre Literatura Fantástica Uruguaya" (G.I.L.F.U.) y director de la revista académica Tenso Diagonal (Uruguay), consta de un "Prólogo" y diez capítulos. La "Introducción", que se centra en estudiar la narrativa uruguaya relacionada con lo fantástico entre 1947 y 1960, repasa textos destacables de escritores como Felisberto Hernández y ofrece pertinentes análisis de los principales críticos relacionados con la temática abordada. El año 1947 es relevante pues surgen escritores que se ven como "agentes de cambio" (15) y que son miembros de una nueva generación. Los autores estudiados o nacieron en Uruguay o son extranjeros que tuvieron una década de residencia en el país.

A la introducción le sigue el capítulo II, en el que se estudian los antecedentes de la narrativa uruguaya hasta mediados del siglo $\mathrm{XX}$, estableciéndose un diálogo con lo fantástico y los ambientes de los movimientos literarios anteriores. Se abarca una época poco estudiada y marginalizada desde la perspectiva de lo fantástico, de manera que se señalan las corrientes literarias y de pensamiento predominantes, sin pasar por alto la obligada mención de los movimientos independentistas en Hispanoamérica. Paolini se apoya en críticos como José María Oviedo (quien incide en la superposición de ciertos movimientos literarios), repasa aspectos esenciales del modernismo y las vanguardias y estudia narraciones de Vicente Salaverry, María E. Crosa de Roxlo, José Pedro Bellán y Horacio Quiroga, entre otros, autores que revelan una atracción por lo fantástico desde diversas perspectivas.

En "El entorno sociocultural uruguayo del medio siglo XX" se ofrece un panorama del ambiente cultural de esa época en que diversas transformaciones propician la aparición de jóvenes escritores en el medio sociocultural de Uruguay. Dentro del subapartado del entorno cultural surge la reglamentación de los Premios Nacionales de Literatura y de Música y se habla de una "nueva literatura uruguaya" (63), título asimismo del artículo de Carlos Maggi publicado en el primer número de la revista montevideana Escritura (1947). El capítulo estudia la falta de empresas editoriales en el país, pero aumenta la influencia de las literaturas extranjeras (Rama, 1959). El advenimiento y posterior consolidación de la revista Marcha permitió la difusión de la obra de jóvenes escritores como Juan Carlos Onetti (quien dirigió la página literaria de dicha revista) (77). De manera puntual se señala 1960 como el año bisagra que señala "un punto de Maduración" (81). Estamos ante una literatura cuyos creadores provienen de la clase media, grandes protagonistas de un medio que atraviesa profundos cambios.

La siguiente sección recoge las teorías más destacables de lo fantástico, subscribe los nombres conocidos por la crítica a nivel internacional y debate la novela psicológica y el relato fantástico, en concreto, situando en el merecido lugar de lo fantástico a Adolfo Bioy Casares y a Jorge Luis Borges. Paolini destaca los textos y teorías más sugerentes de ambos escritores, señalando las lindes y conexiones entre la literatura realista y la psicológica, sin olvidar la conocida opinión de Borges ante el debate entre el realismo y lo fantástico. Las diversas conferencias del autor argentino en Uruguay favorecen su influencia en los escritores uruguayos envueltos en el aura de la literatura fantástica. Se realza la capacidad analítica expuesta ante las teorías de Roger 
Caillois (1996), que tratan de lo maravilloso y lo fantástico, Louis Vax, quien ya en Arte y literatura fantásticas (1960) no se arriesga a definir lo fantástico, y prefiere lo "preternatural". No podía faltar un breve y sutil análisis de la teoría de Tzvetan Todorov. Otros trabajos estudiados son los de Rosie Jackson (1981), Susana Reisz (1989), Ana María Barrenechea (1957), Jean Bessière (1974), Jaime Alazraki (1990) y Rosalba Campra (2008). Aparecen subapartados que abarcan categorías colindantes a los fantástico, la ciencia ficción, el realismo mágico y el real maravilloso. Lo insólito ocupa lugar como subgénero de lo fantástico y se va perfilando con más recurrencia en secciones sucesivas del libro.

En "La producción del cuento relacionado con lo fantástico entre 1947 y 1960" se lleva a cabo el estudio de relatos relacionados con dicho género literario (referidos en el corpus del periodo de tiempo investigado). Se dedica un subapartado a Felisberto Hernández, con detallados análisis de cuentos como "El balcón”, "El acomodador", "Muebles «El Canario»", "Las Hortensias” o "La casa inundada", sin olvidar el mundo de los objetos, a menudo humanizados y tan relacionados con la literatura fantástica. Paolini pone de relieve la presencia del hecho insólito que se expone en diferentes planos y profundiza en aspectos de lo desconocido, el doble, el miedo, la enfermedad y los presagios de la muerte. Entre otros autores surgen los nombres de María E. Crosa de Roxlo, Emma Risso Platero, José Enrique Etcheverry, Mario Benedetti y Armonía Somers. Paolini estudia sus cuentos desde la pertinente visión crítica que incluye el psicoanálisis, siempre teniendo presente aspectos insólitos y a menudo la aparición de lo sobrenatural, el sueño y lo monstruoso.

El capítulo "La literatura vinculada con lo fantástico en el contexto del medio siglo XX" muestra un interesante estudio crítico que ofrece aspectos teóricos de especialistas en literatura uruguaya como Giselda Zani, quien destaca la labor y aptitudes literarias de los escritores de la época, destacándose la "subjetividad". Llama la atención que un cuento como "Los altos pinos", de dicha autora, sirve para entablar apreciaciones sobre la crítica literaria uruguaya (304). En el apartado "Lecturas e intertextos" se alude a aquellos escritores de literatura fantástica cuyas traducciones inspiraron a escritores uruguayos que provenían del ambiente cultural de la época. Los numerosos textos expuestos, nombres de autores y títulos de antologías relevantes, confieren una rica fuente de información que incluye entrevistas literarias. En el subapartado "Marginales y marginados" se saca a colación la escasa o nula visibilidad de muchos escritores, como ha destacado Celina Manzoni (1999), pero no obstante, "la producción de cuentos vinculados con lo fantástico en Uruguay, durante los años cincuenta del siglo pasado, presentó el empuje más significativo hacia ese momento" (340).

"Lo fantástico literario. Perspectivas", séptimo capítulo de la monografía, se enfoca en cuentos que se dividen en dos conjuntos: el primero corresponde a "las narraciones que se muestran como epígonos de los cánones de la narrativa universal que inauguran fundamentalmente los románticos, y que alcanzan a las visiones en esencia aplicadas hasta los iniciales años del siglo $\mathrm{XX}$ " y, por otro, "los cuentos que revelan elementos originales a través de una prosa con derivaciones complejas (...)" (341). El subapartado "Fronteras del realismo y de la realidad" ofrece replanteamientos enriquecedores, vinculantes a este estudio, de trabajos de Aristóteles, György Lukács, Guy de Maupassant, Hans-Georg Gadamer y Paul Ricoeur. Paolini reincide en que estamos ante una literatura "que conlleva la transgresión del orden establecido" (350) y, aunque de nuevo 
alude a alguno de los cuentos de Felisberto Hernández, añade sutiles pinceladas críticas cuando los analiza. En el subapartado "Ominoso y otredad" se repasan con detalle textos de Sigmund Freud relacionados con el tema en cuestión, marcándose lazos insustituibles entre lo fantástico y el psicoanálisis.

El libro reseñado da fe de una rigurosa labor académica, siendo el producto de una larga investigación que lo sitúa como texto esencial y clave para los estudiosos de literatura fantástica. Es más, la extensa y completa bibliografía y el anexo que ofrece un valioso "Índice de la narrativa breve uruguaya (1947-1960)" es la guinda final que perfila un trabajo que va más allá de cumplir con los objetivos de analizar "Lo fantástico en el cuento uruguayo". El meditado análisis refleja una detallada labor crítica de la literatura fantástica y de lo insólito que invita a académicos y a estudiantes universitarios a introducirse, profundizar y enriquecer conocimientos sobre autores y cuentos uruguayos, muchos de los cuales son desconocidos para un lector que acaba complacido con un trabajo escrito con admirable rigor académico. Estamos, sin duda, ante el libro más completo publicado hasta la fecha en el contexto de la literatura fantástica uruguaya del siglo XX.

Rafael Cabañas Alamán Saint Louis University, Madrid Campus rafael.cabanas@slu.edu

DOI: https://doi.org/10.24029/lejana.2020.14.892

Recibido: el 2 de agosto de 2020

Aceptado: el 26 de octubre de 2020

Publicado: el 26 de febrero de 2021

(C) Rafael Cabañas Alamán

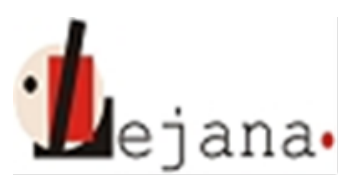

http://ojs.elte.hu/index.php/lejana

Universidad Eötvös Loránd, Departamento de Español, 1088 Budapest, Múzeum krt. 4/C 